\title{
Reform of the Professional Experimental Teaching and Practice of the Students' Quality and Ability Training
}

\author{
Reform of the Professional Experimental Teaching
}

\author{
Jinzhe $\mathrm{He}$ \\ College of Biological and Environmental Engineering \\ Zhejiang University of Technology \\ Hangzhou 310014, China \\ hjzgd@zjut.edu.cn \\ Yanping Cai \\ College of Biological and Environmental Engineering \\ Zhejiang University of Technology \\ Hangzhou 310014, China \\ caiyp@zjut.edu.cn
}

\author{
Tingting Feng \\ College of Biological and Environmental Engineering \\ Zhejiang University of Technology \\ Hangzhou 310014, China \\ sam.xine@gmail.com \\ Huagui Liu \\ College of Biological and Environmental Engineering \\ Zhejiang University of Technology \\ Hangzhou 310014, China \\ liuhuagui@zjut.edu.cn
}

\begin{abstract}
This paper studied how to improve the quality of personnel training, strengthen the professional teaching experiment, and establish a student-oriented professional experimental teaching mode, in order to comprehensively improve the students' knowledge, ability and quality. The reform which combined firm foundation, wide knowledge, broad vision and high-quality, penetrated the entire professional experimental teaching reform. It focused on teachers' "teaching", stimulated students' "learning" and "training", and students' "thinking" to lay a good foundation for the students' work. A series of experimental teaching curriculum reform implemented to improve the ability and quality of students.
\end{abstract}

Keywords- professional experimental teaching; ability; quality

\section{INTRODUCTION}

With the development of economy and society, employer more appeared to employ the graduated students of more multi-type, multi-level, and they increasingly focuses on the knowledge, ability and quality of students. The college always develops high-quality students, and strives to train their innovative ideas and ability. In fact, however, students often expose many problems in social practice, employment interviews even starting work, such as unrealistic expectations and lack of underlying the ability to work. Many college students started to work, they often lamented that their own quality and expertise proficiency can not adapt to the needs of social development. Similarly, the evaluation of many employers for the graduated is not high. These caused that college students' survival devalued.

As we all know, university of science and engineering education has accumulated a deep tradition of experimental teaching, but this mode often use the years of curriculum content, and those outdated teaching materials, single teaching methods often lead to out of step with the development needs of the community. Coupled with students have too much examination-oriented education that is to say they lack the practical ability training, therefore many college students are difficult to adapt the needs of the job market. The disjoint of academic education and social have often been criticized. In

recent years, it had also been improved rapidly to follow the reform of university course, experimental teaching concept and mode in college science and engineering education. They established a dominant values and goals, which reveals an effective way to ensure quality education.

\section{THE THOUGHT OF THE EDUCATIONAL REFORM OF PROFESSIONAL EXPERIMENTAL TEACHING}

With the years of experimental teaching, we deeply appreciate either "teaching" or "learning", there are many questions needed us to explore and reform, such as how teachers consciously cultivate and improve students comprehensive quality and foundation work ability in the process of teaching experiment, how we find a good way in the current experimental teaching curriculum and how we promote the improvement of the teaching experiment to improve students' ability of the overall quality. The essence of teaching method is inspiration and the essence of learning method is migration.

Secondly, when we talk about students' overall quality of training, we generally tend to create the atmosphere of their ideological and moral humane quality education. However, relevant expertise and the simple quality education, which is fostered by the technological innovation capacity, is difficult to match with the needs of society. Experimental curriculum tends to simplex learn experimental method, focuses on the experimental results, and trains students mechanically followed with the experimental procedure. While for the knowledge what 
students have learned, it is lack of comprehensive training opportunities to practice, to use, and to enhance the level of expertise by some scientific experiments. The contents of many teaching experiment are confirmatory and demonstrable experiments. Moreover, the experimental project sets up in accordance with the curriculum, so the content is duplicate and decentralized. Those experiments which can conducive to students' practical and innovative ability are penurious. The modern experimental teaching mode and techniques of broad-knowledge and low-levels are also scarce. This lack weakens the function of the experimental teaching in personnel training, and the results can't achieve.

Currently, students lack basic ability training in practice work. In the experimental teaching, some students overlook some basic and detail problems, such as how to reduce the relative errors of weighing, how to use quantitative instrument, how to headling the leakage problem of burette, analyzing sample or sampling, recording and treating the experimental data, and so on. We often find that the students make a stupid mistake or fail to deal with problems, even treat some basic work very casual and nonstandard in experiment. The quality of students is accumulated bit by bit, therefore we should start from the details to develop students' ability to work and to improve the overall quality of them. In the experimental teaching, while the basic training arranged to students is not enough. Some teachers neglect details in experiment, and lack the training of students' rigorous work attitude, so it is not surprising that students have high IQ but low ability.

We often talk about that we should strive to cultivate students' sense and ability of innovation, but both of them are built on a solid knowledge base and extensive knowledge level. At present, in university, many experimental curriculum contents unchanged for years, but the developments of science and technology are changing rapidly. In addition, many modern experimental techniques continue to introduce to the school, research institutes and enterprises, so how should we introduce the advanced experimental techniques in a timely to the experimental curriculum, and set up a opening laboratory platform to develop students' ability, broaden their vision and inspire their aggressive awareness and innovative ability, which is a question we need consider urgently in the teaching profession experimental course. In our professional experimental teaching of curriculum reform, the main idea is centered around the training concept of firm foundation, wide knowledge, broad vision, high quality and strong ability.

\section{THE MODULE ESTABLISHMENT OF EDUCATIONAL REFORM OF FIRM FOUNDATION}

Thick foundation primarily focuses on training students' basic experimental work capacity, precise work attitude and style, as well as improving students' own quality in the details. There are numerous cases show that only with profound professional foundation can help the student to have a chance to grasp the major needs of the community and make a significant innovation in certain environment.
The setting of basic module should focus on the weak point of students' experimental ability and its focal point is the design of the contents of experimental basic module, then it must accentuate students' basic, normative and detail experimental training. The experimental teaching must stress teacher's teaching, student's learning and the training which penetrate in the basic experimental contents, furthermore, it should make the students improve personal basic quality of work as the starting point.

In our basic module of experimental teaching, the training which focuses on the students' basic operation of experiment has been put in the first place. For example, during the analysis of experiment, how much sample we weighted would be suitable ? What's the impact that the weight of samples bring out on the results of the analysis error ? What's kind of relationship between experimental results accuracy and these operation which are the used analytical methods, the type of instrument and operation, the effective number of weighing and so on. How to reduce the relative error caused by the students during analysis? This requires us guide students step by step to think about what are the sources of error in the process of teaching? Which method can reduce these errors? If we want to get the correct results, which key steps we should do well? Another example is during the sampling some students often take a spoon or a pipette, then directly put into the original reagent bottle. As for whether the spoon or pipette is clean, whether the original reagent bottle will be polluted, or whether it would bring analytical error, they will not consider carefully. In addition, in the sample preparation process, how should students write label and experimental record, and whether the students' experimental record can reflect the retrospection, replicability and authenticity during the experiment. These often can reflect the students' basic quality. The training of experimental skills is actually the training of scientific quality, so it must be treated strictly. In the elementary training stage, the accuracy of students' experiment results is often closely associated with whether the operation is meeting the procedures. The solid basic skill is a prerequisite for doing various experiments and work, and it is also a foundation that students can have a great accomplishment at themselves disciplinary professional field.

Theory is founded on the basis of experiments, so it requires rigorous scientific design and true record of experimental results. Many seemingly simple experiments also demand a rigorous and honest scientific research quality. Rigorous scientific design is the premise of the experimental capacity training. For example, during analysis experiments, we can design a set of normative scientific experiments steps, and the necessary experimental operating procedures to develop students' good work habits and rigorous scientific experimental style from the beginning to the end of the experiment such as sampling, weighing sample, handling sample, preparation of standard solution and the use of instrument, which can correct the arbitrary and fallacious method of operation. For some larger error on data, we must analyze the cause of the error, and operate or record again, finally collect relational data, make 
mathematical statistics and calculate the corresponding error. These bases of experimental training are conducive to developing students' awareness of the rules and strict logical thinking ability, accumulating basic skills and training special skills.

Details are the key to success. In the experimental teaching process, teachers' knowledge is the basis of starting teaching and the basis of effective teaching. How to teach is inseparable linked with teachers' continuous learning, experience and the wisdom obtained from the front-line teaching practice. What's more, the most basic details are also important. Through a range of basic experimental design, combined with firm foundation, wide knowledge, broad vision and high-quality reform customary, we carried out the reform of experimental teaching materials. It focuses on teachers' "teaching", stimulated students' "learning" and "training", and students' "thinking" to lay a good foundation for the work for students. A series of experimental teaching curriculum reforms implements to improve the ability and quality of students. At the same time, if the students have good basic skills, it is the necessary guarantee of obtaining achievement no matter what their work is. For the field of scientific research, the student, who can use methods of academic disciplines resolved significant practical problems arbitrarily, is the skilled personnel who master the disciplines deep skill.

\section{EXPERIMENTAL TRAINING FOR STRENGTHENING STUDENTS' ABILITY}

Ability cultivation is the main line of experiment training. The experiment teaching mode, which is hierarchical, phased, multi-module and step-by-step, focuses on training the students' experimental, learning and consolidated ability, and innovation consciousness, then form a multi-level, multi-faceted practice teaching system. The ability training is not the experiment itself but through the experiment can be know what should be learned and what's the revelation should be obtained, even the inferences can be drew. According to the multi-level teaching or the experimental connotation, experimental teaching can divide into four levels, including training of basic skills, training of technical competence, training of comprehensive ability systematically and research of graduation thesis design. The multi-faceted teaching mainly make the curricular activities, professional practice, extra-curricular activities and practice in enterprise as the part of practice teaching, and carry out a wide range of practice teach training.

In our teaching reform of course content, the systemic training of the experimental capabilities is of great importance. The content of opened experiment is not only simply teach students experimental methods, but also pay more attention to think what can students learn, whether students can analyse the problem produced in experiment, as well as whether teachers can put inspiring questions in experiment. We selected topic and compiled experimental textbooks for experiment from these aspects which are the operating techniques of various units, the common type of industry, the modern experimental techniques and the ability of students' research. The content of textbooks should pay attention to introduce and increase the proportion of integrated design experiment. Through the teaching experiment, systematic experimental contents have been designed, which focus on strengthening students' basic skills training, elaborative faculty, manipulative ability, and comprehensive quality of scientific research. At the same time, we creat the platform of basic and modern experimental technology for students, so that students have ample opportunities for the training of the experimental manipulations.

For example, in the food analysis of experiment, we open seven experiments, a total of 32 credit hours. In this course, we mainly focus on developing students' analytical skills, and we elaborate some selected representative analysis of projects in food industry including sampling, various methods of sample preparation, sample analysis, the operation of various types of analytical instruments in food detection, the accuracy of analytical methods, and data processing. The content of experiment covers some common analysis of experiments in the food industry, such as analysis of sugars, nitrogen, nutritive material, metal trace elements, food additives, as well as analysis of food sensory and physical nature. In the experimental analysis course, we set up the synthetical experiments as much as possible. For example, in the classic Fehling experiment, we not only analyse reducing sugar, but also analyse nonreducing sugar, the determination of conversion coefficient and standardized coefficient of non-reducing sugar and reducing sugar, and the calculation of the total sugar content, which can reflect the preciseness, scientificity, complexity and integrality of the entire analysis process. For design of the experimental content, we focus on the process of capacity training rather than the results. We increase the experimental ability training of analytical basis, for example, the relationship with the quantity of the sample, effective digits, the selected weighing apparatus and analytical error. Of course, there are many other knowledge and technologies like blank test, recovery test, equipment debugging and so on, which have received very good teaching results. Our experiments not only focus on traditional techniques, but also focus on the modern common food analysis techniques.

In the food technology experiment course, we open eight experiments, a total of 32 credit hours. In this course, we mainly add common processing technology in the food industry, such as the technology of baking, refining sugar, fermentation, puffed extrusion, homogenization and sterilization. In experiment, we emphasize the application ability of these processing technologies and the explorative design of product.

In synthetical experiment, we open two professional integrated design experiments that it takes continuous 2 weeks. When select the theme of these two experiments, we primarily focus on the comprehensive application of multiunit operation, high-tech and analysis detection technology. We also strive to the selected theme have vast knowledge, strong relevance of knowledge, cutting-edge knowledge of the subject, novel experimental program and many unit operations. It belongs to a difficult comprehensive practical course for learning and teaching. During the experiment, 
students should not only grasp these knowledge such as enzyme engineering, microbiology, biochemistry and some food industry relational technology, but can use the operation skills such as extraction, hydrolysis, purification, filtration, concentration, drying, membrane separation, distillation, supercritical fluid extraction, the rheological performance testing, physical properties testing, orthogonal experiment and response surface method for experimental optimization method design and Origin software for charting. From writing the opening report, designing experimental program, unit operations, processing the experimental data to completing the experimental papers, each procedure is focused on training the students' ability. In this process, students select a topic and look up relational literatures, then they design experiment project and write the opening report in accordance with experimental requirements. After the teachers checked the reports, students start to do the experiment, finally submit a normative experimental report and the original experimental records.

Through the three above mentioned experimental links, many students reflect that each experimental content is abundant and intersperse with some complex training, but it greatly stimulate their desire to learn. Sometimes the experiment fail, students discuss with teachers consciously and analyze the reasons for the failure then do this experiment again. Through the systematic and comprehensive learning, students can have a clearer thinking for experiments and learn a lot of working methods and technology to stimulate their interest in learning, improve their experimental research skills, learn the scientific research method, and open up their idea for research work. At the same time, it also cultivate students' skepticism, sparke their thinking of many experimental problems, stimulate students' enthusiasm for innovation, and enhance their confidence of doing well work. In turn, it promote teachers to constantly improve the educational reform of experimental teaching, and explore how to train the students better to have a good professional quality and ability, which meet the contemporary society need.

\section{THE IMPLEMENTATION OF THE QUALITY EDUCATION}

How to transform the knowledge education to the quality education is a question that many education experts have been subject to explore. In many years of experimental teaching, we profoundly realized the quality education should not only include the students' knowledge level, but reflect the importance of students' practical ability. The State Council promulgated the "Education Planning Outline" in 2010. The strategic theme of our future education reform is "adhere to the people-oriented, comprehensive implement quality education". Quality education has been promoted to the national education strategy, which is widely recognized and implemented. Training model of the 21 st century is a comprehensive training of knowledge, ability and quality. With higher education in China toward public education from elite education, we need to establish the concept of quality education and pay attention to transform knowledge to ability, so that the knowledge, ability and quality can interact and develop harmoniously in talent overall structure. Quality education will play an important role in many aspects. For example, university graduates how constantly adapt to job market, and ever more society competitive, more realize to their social values and personal values.

In our professional teaching course of experiment, we need to improve the quality of personnel training, strengthen the professional teaching experiment, and establish a suitable professional experimental teaching mode for student devotement, in order to comprehensively improve the knowledge, ability and quality of students. In the experimental teaching system, we not only have a solid fundamental knowledge and strong skills training, but also need to focus on a wide range of knowledge. Similarly, we not only focus on the learning of professional experimental techniques, but also introduce the knowledge of related fields in experimental teaching to expand students' range of knowledge. In the module of wide knowledge teaching, we strive to introduce some subject-related and cross-disciplinary technical contents to students in limited hours. In the curriculum provision of experimental teaching, for an established experiment, teachers also should introduce the experimental knowledge of related technology field. In the curriculum provision of series experimental projects, it not only involves the food industry commonly used experimental techniques, but introduces related professional experimental techniques for experimental teaching system to have wide coverage and strong practicability. The broad vision means that we introduce the modern experimental high-tech, construct teaching platform of experimental teaching, and create a good experimental environment of modern equipment technology in our teaching experiments. It also need sustained and effective provide the space of using instrument for students. Through the comprehensive experimental design, students must have the basic training of scientific research and ability to work. The teaching philosophy that cultivate students' ability and quality should penetrate in experimental teaching system such as looking up data, designing experimental program, making raw materials to production, applying the comprehensive experimental technology and completing the experimental papers report. In recent years, many of our graduates or postgraduate, in terms of the overall quality and the ability of work and practical, obtained the praise of many employers and universities.

High education is the highly creative process, so it should direct, inspire, guide, develop and train students' creative talent. Quality education is a new idea and concept, rather than a specific course or method. It comprehensively improves the basic quality of all students through a variety of teaching and learning. Additionally, it must respect the students' subjectivity and focus on the development of human intellectual potential.

With the rapid development of modern science and technology, students must have the strong competitive edge in the job market, especially the engineering students. Of course, our teaching experiments also need continuous reform. We should pay attention to the experiment teaching 
quality, promote experimental teaching reforms, improve the level of experimental teaching, and strengthen the use of new experimental methods and advanced experimental techniques. Only the practice teaching platform that adapt to contemporary technology had been built, students can have a strong competitive edge in the job market.

\section{ACKNOWLEDGMENT}

Food applications and innovative talents of Experimental Teaching System Reform Research and Practice (JG1233).

\section{REFERENCES}

[1] X. Lou, S. Zhou, and L. Wu, "The analysis of competitiveness of graduate employment," Explor. Educ. Dev., vol. 13, pp. 49-52, Jul. 2005.

[2] B. Wang. "To focus on solving the problems of "unrealistic expectations" of college students," Value Eng. , vol. 25, pp. 271-273, Jun. 2012.

[3] L. Wang. "Briefly talk about the form and structure of higher education in China," High Educ. Chin., Vol. 11, pp. 34, Spet. 2006.

[4] H. Gan, D. Q. Xu. "The study of training engineering applied talents of high quality," High Educ. Eng. , Vol. 6, pp. 44-48, Jun. 2010.

[5] Z. Yang, L. Xing, Y. B. Sun. "The employment of predicament and breakthrough of university graduates," Forum Contemp. Educ., Vol. 8, pp. 75-77, Aug. 2010.
[6] P. Huang. "The exploitation of the experimental curriculum and teaching: A new way for education reform," Explor. Educ. Dev., Vol. 18, pp. 49-53, Sept. 2009.

[7] Q. Xu, J. Z. Peng, F. Q. Ye. "College Physics Experiment Teaching Reform and Practice in the new personnel training model," High Educ. Sci. , Vol. 2, pp. 107-110, Feb. 2012.

[8] G. Qing, D. Huang, F. Lu. "Constructing experimental teaching system of innovative personnel training," Lab Res. Explor. , Vol.1, pp. 101-104, Jan. 2012.

[9] Y. H. Zhu, Z. H. Yang. "Constructing boutique experimental project to promote innovation ability," Lab Res. Explor. , Vol. 1, pp. 7-10, Aug. 2008.

[10] Y. Z. Zhu, J. C. Li. ""Talent Education" of postgraduate: A aspect of education need urgent attention," Degrees Graduate Educ. Vol. 9, pp. 1-7, Mar. 2010.

[11] X. Cao, L. Yao, S. Z. Huang. "The discussion for the countermeasures of improving the Higher Education teaching effectively," High Educ. Explor., Vol. 2, pp. 70-75, Mar. 2012.

[12] Z. G. Yuan. "Adhere to the people-oriented, comprehensive implementation of quality education," Chin. Educ. Daily, Vol. 1, pp. 15, Aug. 2010.

[13] L. Yu. "Structural analysis of the quality of college teachers in New era," Educator, Vol. 15, pp. 78-79, 2012.

[14] Y. Cai. "The revelation that Jobs bring to Chinese College Students' Quality Education,” Hua Zhang, Vol. 12, pp. 107, Jul. 2012.

[15] L. Han, J. K. Gu. "The discussion for the role of university courses in the culture of students' quality," J. Arch. Educ. Inst. High Educ., Vol. 3, pp. 35-38, Jun. 2010. 